\title{
EFEITO DA CONCENTRAÇÃO NA DILATAÇÃO VOLUMÉTRICA DO SUCO DE AMORA-PRETA
}

\author{
EFFECT OF CONCENTRATION ON VOLUMETRIC EXPANSION OF \\ BLACKBERRY JUICE
}

\author{
César Augusto Canciam \\ Universidade Tecnológica Federal do Paraná - Campus Ponta Grossa, Avenida Monteiro Lobato, km 04, Ponta Grossa, \\ Paraná, CEP: 84016-210. E-mail: canciam@utfpr.edu.br
}

\begin{abstract}
RESUMO
O estudo da dilatação térmica em líquidos é feito somente em relação à dilatação volumétrica, sendo importante o conhecimento do coeficiente de expansão térmica. O presente trabalho teve por objetivo verificar o efeito da concentração de sólidos totais nos valores do coeficiente de expansão térmica do suco de amorapreta. Para tanto, por meio da análise de regressão linear da densidade de cada suco em função da temperatura, foi possível predizer os valores para o coeficiente de expansão térmica. Esses dados foram estimados de outro trabalho. Os valores encontrados para o coeficiente de expansão térmica variaram de $4,0420 \times 10^{-4} \mathrm{C}^{-1}$ $\left(58,4^{\circ} \mathrm{Brix}\right)$ a $5,1890 \times 10^{-4 \circ} \mathrm{C}^{-1}\left(9,4^{\circ} \mathrm{Brix}\right)$. O intervalo de temperatura considerado foi de 10 a $70^{\circ} \mathrm{C}$. Constatou-se que, à medida que se aumentou a concentração de sólidos totais, diminuiu-se o valor do coeficiente de expansão térmica. Provavelmente, isso esteja associado ao tipo de ligação intermolecular formado entre a água e os compostos fenólicos presentes no suco de amora-preta. $\mathrm{Na}$ literatura, não foram encontrados valores experimentais do coeficiente de expansão térmica para o suco de amora-preta, o que dificultou a análise.
\end{abstract}

Palavras-chave: Dilatação. Efeito. Concentração. Suco. Amora-preta.

\begin{abstract}
The study of the thermal dilatation in liquids is only made in relation to the volumetric dilatation, being important the knowledge of thermal expansion coefficient. The present work aimed to investigate the effect of total solids on the values of the thermal expansion coefficient of blackberry juice. Therefore, throught the linear regression analysis of the density of each juice as function of temperature, it was possible to predict the values for the thermal expansion coefficient. These data were estimated for other work. The values found for the thermal expansion coefficient ranged from $4.0420 \times 10^{-4 \circ} \mathrm{C}^{-1}\left(58,4^{\circ} \mathrm{Brix}\right)$ to $5.1890 \times 10^{-4 \circ} \mathrm{C}^{-1}\left(9,4^{\circ} \mathrm{Brix}\right)$. The temperature range considered was 10 to $70^{\circ} \mathrm{C}$. It was found that the extent that increased total solids concentration, the values of the thermal expansion coefficient decreased. Probably this is associated with intermolecular bonding type formed between the water and the phenolic compounds present in blackberry juice. In the literature, it was not found experimental values of the thermal expansion coefficient for the blackberry juice, difficulting the analysis.
\end{abstract}

Keywords: Dilatation. Effect. Concentration. Juice. Blackberry.

\section{INTRODUÇÃO}

A expressão "pequenas frutas" é utilizada na literatura internacional para referenciar diversas culturas, como a da amora-preta, do morango, da groselha, da framboesa, do mirtilo, entre outras (Monteiro, 2011). A amora-preta é um fruto de clima temperado, pertencente à família das Rosaceae, gênero Rubus spp. Seu cultivo expressivo ocorre no Rio Grande do Sul, em São Paulo e Minas Gerais (Meneghel et al., 2008; Araújo et al., 2009).

Segundo Jacques e Zambiazi (2011), a produção brasileira de espécies frutíferas de clima temperado é ainda insuficiente para atender à demanda interna e gera a necessidade de importação de 
frutas que, na sua maioria, poderiam ser produzidas no Brasil. A amora-preta é uma opção promissora, uma vez que apresenta uma reduzida utilização de defensivos agrícolas e baixos custos de implantação e de manutenção do pomar.

Além do consumo in natura, o mercado para produtos de amora-preta é gerado a partir do suco clarificado e concentrado, utilizado como base na elaboração de vários produtos, como caldas de sorvetes, geleias, xaropes, bebidas alcoólicas e misturas com sucos de outras frutas (Ferreira et al., 2010).

A amora-preta em estado natural é bastante nutritiva, e fazem parte de sua composição: água (87 a 93\%), carboidratos (6 a 13\%), fibras $(3,5$ a 4,7\%), proteínas $(1,5 \%)$, minerais $(0,19$ a $0,47 \%)$ e lipídeos $(0,03$ a $0,08 \%)$. Dentre os minerais, são encontrados: cálcio, fósforo, potássio, magnésio, ferro e selênio. Além disso, são encontradas as vitaminas A, C, E, B6, B12, tiamina, riboflavina, niacina e ácido pantotênico (Jacques; Zambiazi, 2011).

A presença de compostos fenólicos, tocoferóis, carotenoides e ácido ascórbico na amora-preta confere a essa fruta atividade antioxidante frente aos radicais livres, tais como superóxidos, peróxido de hidrogênio, hidroxila e oxigênio singlete (Antunes, 2002; Duarte-Almeida et al., 2006; Jacques; Zambiasi, 2011).

Dentre os compostos fenólicos encontrados na amora-preta, destacam-se o ácido elágico $\left(\mathrm{C}_{14} \mathrm{H}_{6} \mathrm{O}_{8}\right)$, o ácido gálico $\left(\mathrm{C}_{7} \mathrm{H}_{6} \mathrm{O}_{5}\right)$ e as antocianinas (Jacques et al., 2010).

A Figura 1 ilustra as estruturas químicas dos ácidos gálico e elágico.

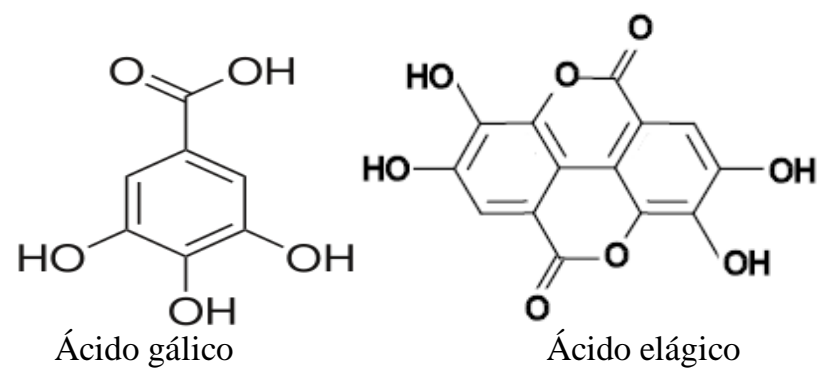

Figura 1: Estrutura química dos ácidos gálico e elágico Fonte: Colpo, 2012; Degáspari et al., 2005.

Com relação às antocianinas encontradas na amora-preta, destacam-se os compostos cianidina 3-glucosídeo, cianidina 3-rutinosídeo, cianidina 3-malonil-glucosídeo e cianidina 3-dioxalilglucosídeo. Dentre as citadas, a amora-preta apresenta alto teor de cianidina 3-glucosídeo (Ferreira et al., 2010).

A Figura 2 ilustra a estrutura química do composto cianidina 3-glucosídeo.<smiles>OC[C@H]1O[C@@H](Oc2cc3c(O)cc(O)cc3[o+]c2-c2ccc(O)c(O)c2)[C@H](O)[C@@H](O)[C@H]1O</smiles>

Figura 2: Estrutura química do composto cianidina 3-glucosídeo

Fonte: Bobbio; Bobbio, 2001. 
As antocianinas compõem o maior grupo de pigmentos solúveis em água do reino vegetal e são estudadas como agentes da coloração natural em alimentos. Também são responsáveis pelos tons compreendidos desde a coloração vermelha até a coloração azul em muitas frutas, legumes e hortaliças (Lopes et al., 2007).

De acordo com Souza e coautores (2007), dados de propriedades físicas e térmicas de sucos e polpas de pequenas frutas são escassos na literatura. A dilatação térmica, a capacidade calorífica e a condutividade térmica são propriedades associadas à resposta ou reação dos materiais devido à aplicação de calor, sendo, por isso, classificadas como propriedades térmicas da matéria. Segundo Jerônimo (2012), essas são propriedades que podem ser padronizadas e dimensionadas por cálculos de engenharia.

Conforme Young e Freedman (2008), Santos e Vieira (2010), Jerônimo (2012) e Canciam (2012), o estudo da dilatação térmica em líquidos limita-se à dilatação volumétrica. Dessa forma, conhecer o coeficiente de expansão térmica permite:

- avaliar os impactos no sistema de medição volumétrico decorrentes da variação da temperatura;

- $\quad$ projetar equipamentos e acessórios considerando a dilatação provocada pelas grandes variações de temperatura;

- auxiliar na estimativa de outras propriedades, dentre as quais, a entalpia de vaporização e a tensão volumétrica;

- $\quad$ estudar a convecção livre que influencia na transferência de calor em tubulações.

O coeficiente de expansão térmica $(\beta)$ indica a variação do volume $(V)$ provocada pela variação da temperatura $(T)$, enquanto a pressão $(P)$ permanece constante, sendo definido como (Netz; Ortega, 2008):

$$
\beta=\left(\frac{1}{V}\right) \cdot\left(\frac{\partial V}{\partial T}\right)_{P}
$$

Em termos da densidade, a equação (1) pode ser reescrita na forma de (Canciam, 2012):

$$
\ln \left(\frac{d_{0}}{d}\right)=\beta \cdot\left(T-T_{o}\right)
$$

onde $d_{0}$ e $d$ correspondem, respectivamente, à densidade na temperatura inicial $T_{0}$ e à densidade na temperatura $T$.

Segundo Canciam (2010), a equação (2) corresponde a uma função afim, ou seja, o gráfico de $\ln \left(\frac{d_{0}}{d}\right)$ versus $\left(T-T_{0}\right)$ fornece uma reta em que o coeficiente angular é numericamente igual ao coeficiente de expansão térmica $(\beta)$.

Esse trabalho teve como objetivo verificar o efeito da concentração de sólidos totais na dilatação volumétrica do suco de amora preta. Para tanto, foram obtidos valores para o coeficiente de expansão térmica do suco de amora-preta em diferentes concentrações de sólidos totais, por meio da análise de regressão de dados estimados da densidade do suco em função da temperatura. 


\section{MATERIAL E MÉTODOS}

A equação (3), obtida do trabalho de Cabral e coautores (2007), relaciona a densidade do suco de amora-preta $(d)$ em função da concentração de sólidos totais $(C)$ e da temperatura $(T)$. Essa equação foi obtida a partir da análise de 160 valores experimentais da densidade em função da concentração e da temperatura. A concentração de sólidos totais variou de 9,4 a 58,4 $4^{\circ}$ Brix, enquanto a variação da temperatura foi de 0,5 a $80,8^{\circ} \mathrm{C}$. O coeficiente de correlação $\left(R^{2}\right)$ obtido para a equação (3) foi de 0,966 .

$$
d=955,4-0,513 \cdot T+5,725 \cdot C
$$

Com base na equação (3), foram estimados os valores da densidade do suco de amora-preta em função da temperatura e da concentração de sólidos totais. Em termos de temperatura, foram consideradas as de 10, $20,30,40,50,60$ e $70^{\circ} \mathrm{C}$. Em termos da concentração de sólidos totais, foram ponderadas as de 9,4, 10, 15, 20, $25,30,35,40,45,50,55$ e $58,4^{\circ}$ Brix.

As Tabelas 1, 2, 3 e 4 relacionam os valores da densidade do suco de amora-preta obtidos pela equação

Para a predição do coeficiente de expansão térmica $(\beta)$ foi desenvolvido um software seguindo a metodologia proposta por Canciam (2012). O software foi desenvolvido na linguagem C++ e realiza a análise de regressão linear de dados de $\ln \left(\frac{d_{0}}{d}\right)$ em função de $\left(T-T_{0}\right)$.

A Figura 3 demonstra o algoritmo do software desenvolvido.

Tabela 1: Densidade do suco de amora-preta $\left(\mathrm{em} \mathrm{kg} \cdot \mathrm{m}^{-3}\right.$ ) obtida a partir da equação (3) para a concentração de sólidos totais variando de 9,4 a $15^{\circ}$ Brix

\begin{tabular}{cccc}
\hline Temperatura $\left({ }^{\circ} \mathrm{C}\right)$ & $9,4^{\circ}$ Brix & $10^{\circ}$ Brix & $15^{\circ}$ Brix \\
\hline 10 & 1004,085 & 1007,520 & 1036,145 \\
20 & 998,955 & 1002,390 & 1031,015 \\
30 & 993,825 & 997,260 & 1025,885 \\
40 & 988,695 & 992,130 & 1020,755 \\
50 & 983,565 & 987,000 & 1015,625 \\
60 & 978,435 & 981,870 & 1010,495 \\
70 & 973,305 & 976,740 & 1005,365 \\
\hline
\end{tabular}

Tabela 2: Densidade do suco de amora-preta $\left(\mathrm{em} \mathrm{kg} \cdot \mathrm{m}^{-3}\right.$ ) obtida a partir da equação (3) para a concentração de sólidos totais variando de 20 a $30^{\circ}$ Brix

\begin{tabular}{cccc}
\hline Temperatura $\left({ }^{\circ} \mathrm{C}\right)$ & $20^{\circ}$ Brix & $25^{\circ}$ Brix & $30^{\circ}$ Brix \\
\hline 10 & 1064,770 & 1093,395 & 1122,020 \\
20 & 1059,640 & 1088,265 & 1116,890 \\
30 & 1054,510 & 1083,135 & 1111,760 \\
40 & 1049,380 & 1078,005 & 1106,630 \\
50 & 1044,250 & 1072,875 & 1101,500 \\
60 & 1039,120 & 1067,745 & 1096,370 \\
70 & 1033,990 & 1062,615 & 1091,240 \\
\hline
\end{tabular}


Tabela 3: Densidade do suco de amora-preta $\left(\mathrm{em} \mathrm{kg} \cdot \mathrm{m}^{-3}\right.$ ) obtida a partir da equação (3) para a concentração de sólidos totais variando de 35 a $45^{\circ}$ Brix

\begin{tabular}{cccc}
\hline Temperatura $\left({ }^{\circ} \mathrm{C}\right)$ & $35^{\circ}$ Brix & $40^{\circ}$ Brix & $45^{\circ}$ Brix \\
\hline 10 & 1150,645 & 1179,270 & 1207,895 \\
20 & 1145,515 & 1174,140 & 1202,765 \\
30 & 1140,385 & 1169,010 & 1197,635 \\
40 & 1135,255 & 1163,880 & 1192,505 \\
50 & 1130,125 & 1158,750 & 1187,375 \\
60 & 1124,995 & 1153,620 & 1182,245 \\
70 & 1119,865 & 1148,490 & 1177,115 \\
\hline
\end{tabular}

Tabela 4: Densidade do suco de amora-preta (em kg. $\mathrm{m}^{-3}$ ) obtida a partir da equação (3) para a concentração de sólidos totais variando de 50 a $58,4^{\circ} \mathrm{Brix}$

\begin{tabular}{cccc}
\hline Temperatura $\left({ }^{\circ} \mathrm{C}\right)$ & $50^{\circ}$ Brix & $55^{\circ}$ Brix & $58,4^{\circ}$ Brix \\
\hline 10 & 1236,520 & 1265,145 & 1284,610 \\
20 & 1231,390 & 1260,015 & 1279,480 \\
30 & 1226,260 & 1254,885 & 1274,350 \\
40 & 1221,130 & 1249,755 & 1269,220 \\
50 & 1216,000 & 1244,625 & 1264,090 \\
60 & 1210,870 & 1239,495 & 1258,960 \\
70 & 1205,740 & 1234,365 & 1253,830 \\
\hline
\end{tabular}

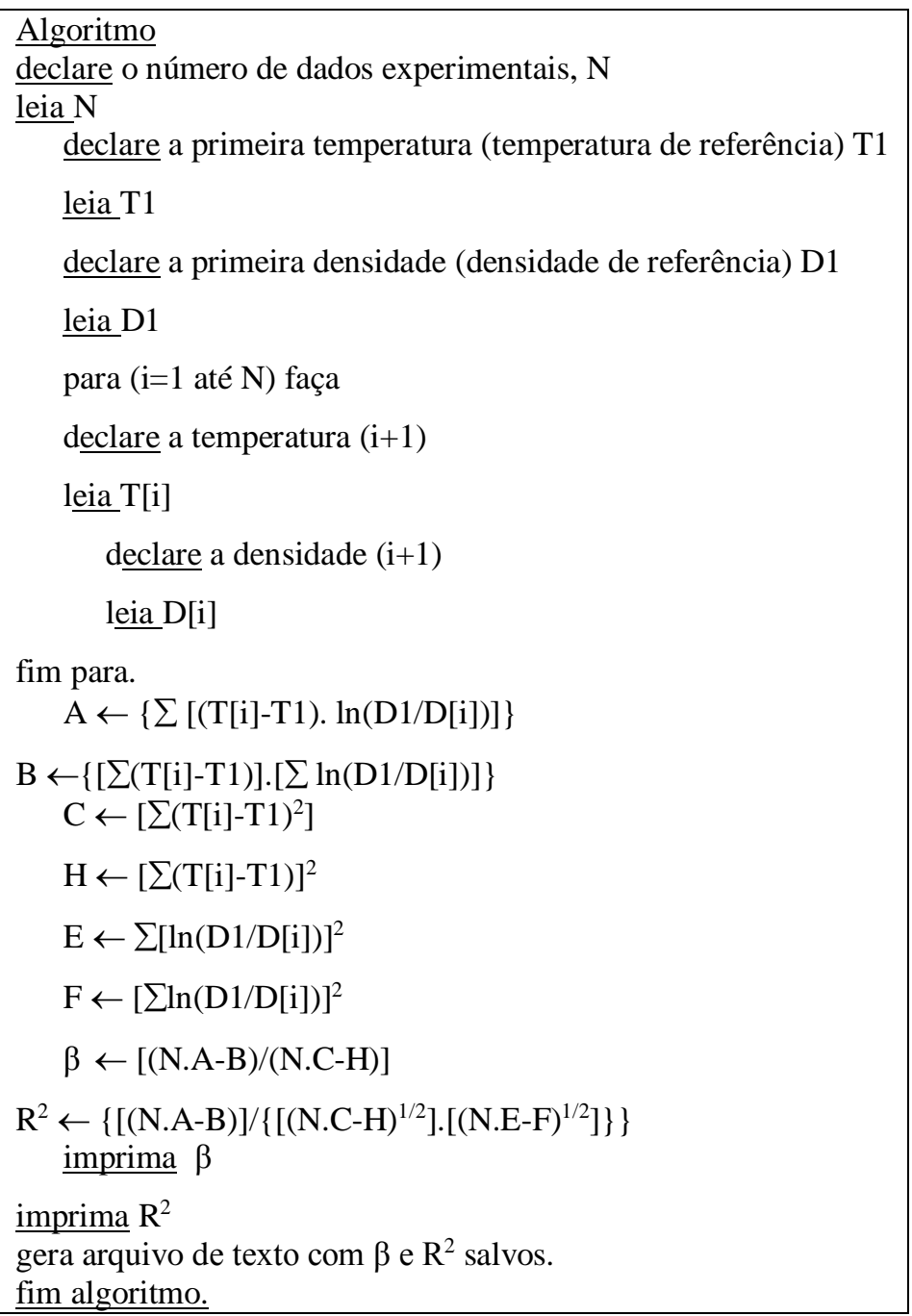

Figura 3: Algoritmo na obtenção dos coeficientes de expansão térmica e de correlação 
Com base nos dados indicados nas Tabelas 1, 2, 3 e 4 e no software desenvolvido, foi possível obter o coeficiente de expansão térmica $(\beta)$ e o coeficiente de correlação $\left(R^{2}\right)$ para cada concentração de sólidos totais.

Nos cálculos, a temperatura inicial $\left(T_{0}\right)$ corresponde a $10^{\circ} \mathrm{C}$ e a densidade inicial $\left(d_{0}\right)$, ao respectivo valor, de acordo com cada uma das tabelas apresentadas.

\section{RESULTADOS E DISCUSSÃO}

As Figuras 4, 5 e 6 ilustram o gráfico da densidade do suco de amora-preta em função da temperatura, nas concentrações de sólidos totais estudadas.

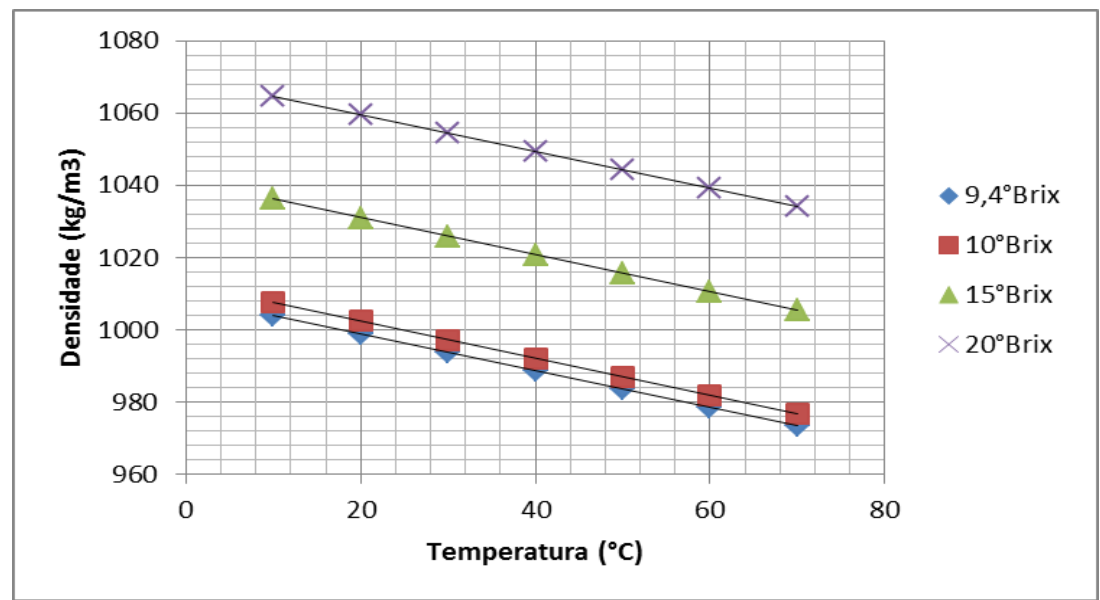

Figura 4: Gráfico da densidade do suco de amora-preta em função da temperatura para a concentração de sólidos totais variando de 9,4 a $20^{\circ}$ Brix

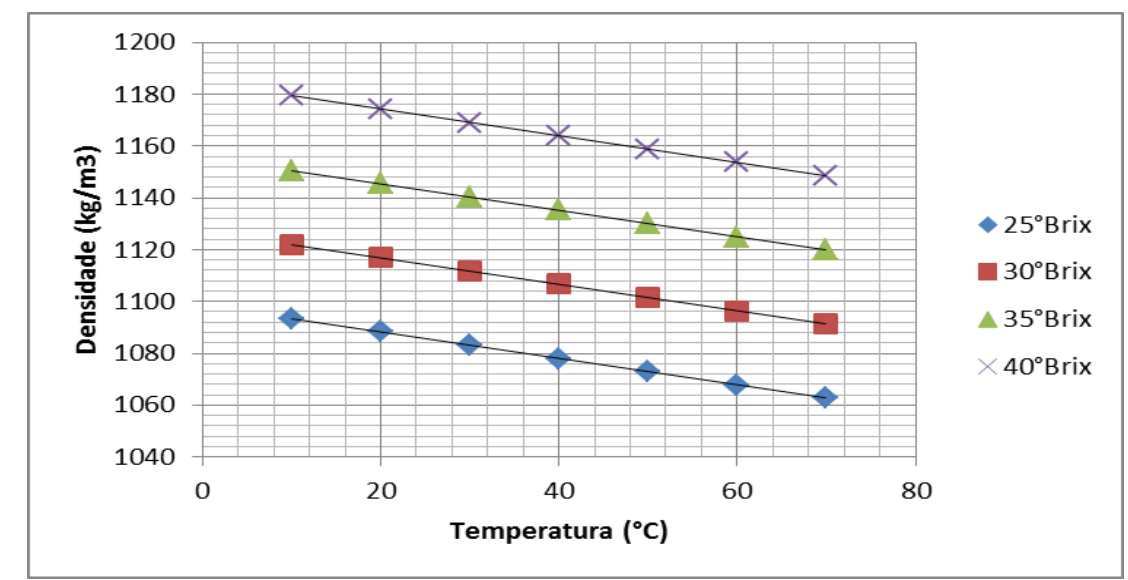

Figura 5: Gráfico da densidade do suco de amora-preta em função da temperatura para a concentração de sólidos totais variando de 25 a $40^{\circ}$ Brix 


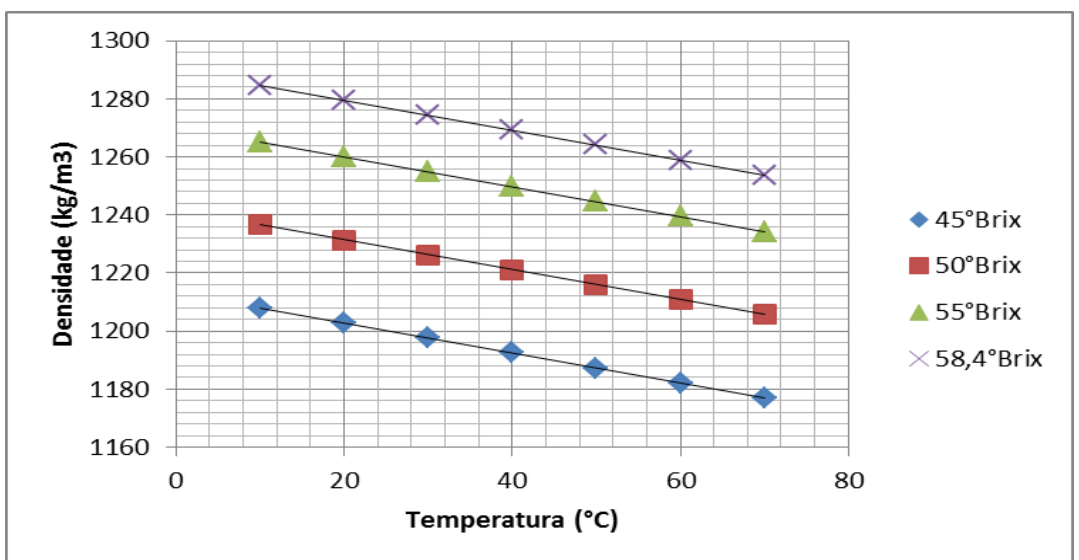

Figura 6: Gráfico da densidade do suco de amora-preta em função da temperatura para a concentração de sólidos totais variando de 45 a $58,4^{\circ}$ Brix

Nas Figuras 4, 5 e 6, verifica-se o comportamento linear entre a densidade do suco de amorapreta em função da temperatura, observando-se que, à medida que se aumenta a temperatura, ocorre uma diminuição da densidade. Tal comportamento também foi obtido no trabalho de Pegorini e coautores (2012), estudando a densidade da polpa de amora em função da temperatura.

A Tabela 5 relaciona os resultados obtidos por meio do software desenvolvido.

Tabela 5: Valores obtidos para o coeficiente de expansão térmica e para o coeficiente de correlação

\begin{tabular}{ccc}
\hline Concentração ( ${ }^{\circ}$ Brix) & $\begin{array}{c}\text { Coeficiente de } \\
\text { expansão térmica } \\
\left({ }^{\circ} \mathrm{C}^{-1}\right)\end{array}$ & $\begin{array}{c}\text { Coeficiente de } \\
\text { correlação }\end{array}$ \\
\hline 9,4 & $5,1890 \times 10^{-4}$ & 0,9999 \\
10 & $5,1710 \times 10^{-4}$ & 0,9999 \\
15 & $5,0260 \times 10^{-4}$ & 0,9999 \\
20 & $4,8889 \times 10^{-4}$ & 0,9999 \\
25 & $4,7591 \times 10^{-4}$ & 0,9999 \\
30 & $4,6359 \times 10^{-4}$ & 0,9999 \\
35 & $4,5190 \times 10^{-4}$ & 0,9999 \\
40 & $4,4079 \times 10^{-4}$ & 0,9999 \\
45 & $4,3021 \times 10^{-4}$ & 0,9999 \\
50 & $4,2012 \times 10^{-4}$ & 0,9999 \\
55 & $4,1050 \times 10^{-4}$ & 0,9999 \\
58,4 & $4,0420 \times 10^{-4}$ & 0,9999 \\
\hline
\end{tabular}

Com relação ao coeficiente de correlação, Pinheiros e coautores (2009) comentam que esse parâmetro mede a interdependência linear entre as variáveis e avalia a qualidade do ajuste, ou seja, quanto mais próximo o coeficiente de correlação for da unidade, melhor o ajuste da reta em relação aos pontos da dispersão.

Lira (2004) fornece uma classificação para as correlações lineares. A autora comenta que a correlação linear é classificada como muito forte quando os valores do coeficiente de correlação são maiores ou iguais a 0,90 e menores que 1,0. Dessa forma, observa-se na Tabela 5, que a correlação linear é classificada como muito forte, para todas as concentrações de sólidos totais estudadas.

A Figura 7 ilustra o gráfico do coeficiente de expansão térmica do suco de amora-preta em função da concentração de sólidos totais. Pode-se observar que à medida em que a concentração de sólidos totais aumenta, o valor do coeficiente de expansão térmica diminui, e essa diminuição ocorre de maneira linear.

De acordo com Lira (2004), essa correlação linear é classificada como muito forte. 


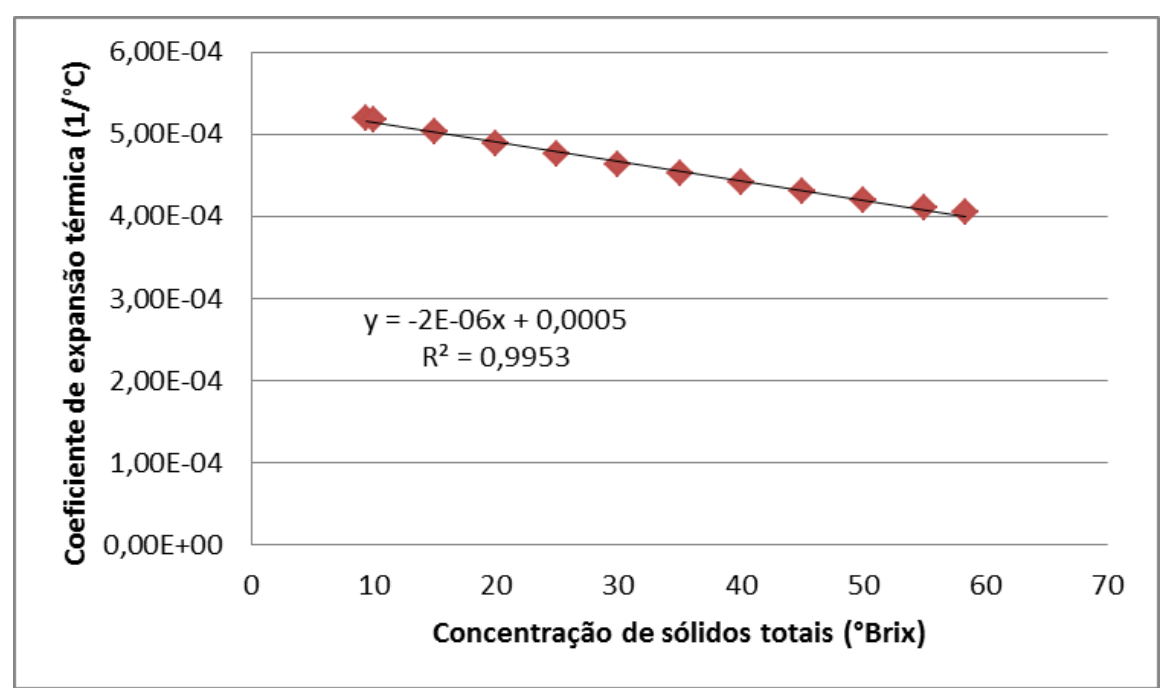

Figura 7: Gráfico do coeficiente de expansão térmica do suco de amora-preta em função da concentração de sólidos totais

Segundo Jerônimo e coautores (2012), o coeficiente de expansão térmica está associado à energia de ligação química entre as espécies (átomos ou moléculas). Materiais em que as ligações químicas são fortes apresentam baixos coeficientes de expansão térmica, tendo em vista que a dilatação térmica está associada à variação assimétrica da energia de ligação com a distância entre as espécies. Durante o aquecimento, as espécies aumentam a frequência e a amplitude de vibração. Como as forças de repulsão são sempre maiores do que as de atração, a distância média entre as espécies também aumenta.

Quanto maior a concentração de sólidos totais no suco de amora-preta, maior a concentração de compostos fenólicos (Monteiro, 2011). Os compostos fenólicos, de acordo com Soares (2002), englobam uma gama enorme de substâncias (fenóis simples, ácidos fenólicos, cumarinas, flavonoides, taninos e ligninas), sendo, em sua maioria, compostos polares muito reativos.

As antocianinas fazem parte do grupo dos flavonoides (compostos fenólicos caracterizados pelo núcleo básico flavílio, ou seja, o cátion 2-fenilbenzopirílio). A molécula de antocianina é constituída por duas ou três porções, sendo uma aglicona (antocianidina), um grupo de açúcares e, frequentemente, um grupo de ácidos orgânicos (Malacrida; Motta, 2006). As antocianinas são moléculas polares, devido à presença de grupos substituintes (hidroxilas, carboxilas e metoxilas) e glicosilas residuais ligados aos seus anéis aromáticos (Lopes et al., 2007).

Pode-se observar, na Figura 2, que a estrutura química do composto cianidina 3-glucosídeo apresenta vários grupos hidroxila $(\mathrm{OH})$. Os ácidos elágico $\left(\mathrm{C}_{14} \mathrm{H}_{6} \mathrm{O}_{8}\right)$ e gálico $\left(\mathrm{C}_{7} \mathrm{H}_{6} \mathrm{O}_{5}\right)$ são exemplos de ácidos fenólicos e, devido à presença de grupos hidroxila (conforme a Figura 1), correspondem a moléculas polares (Bobbio; Bobbio, 2001).

Nas moléculas polares, quando o hidrogênio encontra-se ligado a um átomo pequeno e de forte eletronegatividade (oxigênio, por exemplo), o hidrogênio forma ligações muito fortes denominadas ligações de hidrogênio. As ligações de hidrogênio são consideradas interações intermoleculares fortes, quando comparadas com as interações de Keeson, Debye e London (Netz; Ortega, 2008). Desse modo, nas antocianinas, nos ácidos elágico e gálico e na água, é de se esperar que existam interações intermoleculares do tipo ligações de hidrogênio.

Assim, à medida que se aumenta a concentração de sólidos totais no suco de amora-preta, aumenta-se a interação intermolecular entre a água e os compostos fenólicos (ligações de hidrogênio). Como consequência do aumento dessa interação, sugere-se uma diminuição nos valores do coeficiente de expansão térmica, uma vez que esta aumenta a concentração de sólidos totais no suco de amorapreta. Essa suposição foi comprovada com a Figura 7. 
O coeficiente de expansão térmica mede a variação relativa do volume devido à alteração da temperatura, mantendo-se a pressão constante. Por exemplo, se o coeficiente de expansão térmica de um material é igual a $1,0 \times 10^{-2 o} \mathrm{C}^{-1}$, significa que o acréscimo de 1 grau tem como resultado o aumento do volume em $1 \%$ (Netz; Ortega, 2008).

Seguindo a mesma linha de raciocínio, para cada 1 grau de acréscimo de temperatura, o aumento do volume do suco de amora-preta com $9,4^{\circ}$ Brix é de $0,052 \%$. Para o suco de amora-preta com $58,4^{\circ}$ Brix, o aumento de volume é de $0,040 \%$. Esses valores podem parecer pequenos, mas, se comparados com a água $(0,021 \%)$, o aumento do volume do suco de amora-preta equivale a 2,48 vezes mais (no caso do suco de amora-preta, com 9, $4^{\circ}$ Brix) e 1,91 vezes mais (no caso do suco de amora-preta, com $58,4^{\circ}$ Brix) que o aumento do volume da água.

Buscando na literatura trabalhos associados com a dilatação volumétrica do suco de amorapreta, constatou-se a ausência desse estudo, o que dificultou as análises dos resultados obtidos neste trabalho.

\section{CONCLUSÃO}

A ausência, na literatura, de valores experimentais para o coeficiente de expansão térmica do suco de amora-preta nas diversas concentrações estudadas dificultou a comparação com os valores preditos.

$\mathrm{O}$ coeficiente de expansão térmica do suco de amora-preta variou de $4,0420 \times 10^{-40} \mathrm{C}^{-1}$ $\left(58,4^{\circ}\right.$ Brix $)$ a $5,1890 \times 10^{-4 o} \mathrm{C}^{-1}\left(9,4^{\circ} \mathrm{Brix}\right)$. Em todas as concentrações de sólidos totais estudadas, a correlação linear foi classificada como muito forte.

Os resultados sugerem que com o aumento da concentração de sólidos totais, o valor do coeficiente de expansão térmica diminui, sendo essa diminuição de maneira linear.

A diminuição do coeficiente de expansão térmica em virtude do aumento da concentração de sólidos totais pode estar associada com as interações intermoleculares fortes existentes entre a água e os compostos fenólicos.

\section{REFERÊNCIAS}

ANTUNES, L. E. C. Amora-preta: nova opção de cultivo no Brasil. Ciência Rural, v. 32, n. 1, p. 151$158,2002$.

ARAÚJO, P. F. et al. Influência do congelamento sobre as características físico-químicas e o potencial antioxidante de néctar de amora-preta. Boletim do CEPPA, v. 27, n. 2, p. 199-206, 2009.

BOBBIO, P. A.; BOBBIO, F. O. Química do processamento de alimentos. São Paulo: Varela, 2001. $143 p$.

CABRAL, R. A. F. et al. Rheological and thermophysical properties of blackberry juice. Ciência e Tecnologia de Alimentos, v. 27, n. 3, p. 589-596, 2007.

CANCIAM, C. A. Predição do coeficiente de expansão térmica do óleo de gergelim (Sesamum indicum L.) através da aplicação da análise de regressão linear. E-xacta, v. 3, n. 1, p. 21-28, 2010. 
Predição do coeficiente de expansão térmica do óleo de girassol através da aplicação da análise de regressão linear. Revista Brasileira de Tecnologia Agroindustrial, v. 6, n. 2, p. 852-863, 2012.

COLPO, A. Z. C. Perfil fitoquímico e capacidade antioxidante de extratos de erva-mate (Ilex paraguariensis A. St. Hill.). 2012. 102 f. Dissertação (Mestrado em Bioquímica) - Programa de PósGraduação em Bioquímica, Universidade Federal do Pampa, Uruguaiana, 2012.

DEGÁSPARI, C. H.; WASZCZYNSKYJ, N.; PRADO, M. R. M. Atividade antimicrobiana de Schinus terebenthifolius Raddi. Ciência e Agrotecnologia, v. 29, n. 3, p. 617-622, 2005.

DUARTE-ALMEIDA, J. M. et al. Avaliação da atividade antioxidante utilizando sistema $\beta$ caroteno/ácido linoleico e método de seqüestro de radicais DPPH ${ }^{1}$. Ciência e Tecnologia de Alimentos, v. 26, n. 2, p. 446-452, 2006.

FERREIRA, D. S.; ROSSO, V. V.; MERCADANTE, A. Z. Compostos bioativos presentes em amorapreta (Rubus spp.). Revista Brasileira de Fruticultura, v. 32, n. 3, p. 664-674, 2010.

JACQUES, A. C. et al. Estabilidade de compostos bioativos em polpa congelada de amora-preta (Rubus fruticosus) cv. Tupy. Química Nova, v. 33, n. 8, p. 1720-1725, 2010.

JACQUES, A. C.; ZAMBIAZI, R. C. Fitoquímicos em amora-preta (Rubus spp). Semina: Ciências Agrárias, v. 32, n. 1, p. 245-260, 2011.

JERÔNIMO, C. E. M. Predição do coeficiente de dilatação térmica de naftas pela curva de destilação ASTM. Revista Virtual de Química, v. 4, n. 4, p. 405-412, 2012.

JERÔNIMO, C. E. M.; BALBINO, C. P.; FERNANDES, H. G. Coeficiente de dilatação volumétrica determinados pela curva ASTM em frações de petróleo. Scientia Plena, v. 8, n. 9, p. 1-8, 2012.

LIRA, S. A. Análise de correlação: abordagem teórica e de construção dos coeficientes com aplicação. 2004. 196 f. Dissertação (Mestrado em Ciências) - Programa de Mestrado em Ciências, Universidade Federal do Paraná, Curitiba, 2004.

LOPES, T. J. et al. Antocianinas: uma breve revisão das caractarísticas estruturais e da estabilidade. Revista Brasileira de Agrociência, v. 13, n. 3, p. 291-297, 2007.

MALACRIDA, C. R.; MOTTA, S. Antocianinas em suco de uva: composição e estabilidade. Boletim do CEPPA, v. 24, n. 1, p. 59-82, 2006.

MENEGHEL, R. F. A.; BENASSI, M. T.; YAMASHITA, F. Revestimento comestível de alginato de sódio para frutos de amora-preta (Rubus ulmifolius). Semina: Ciências Agrárias, v. 29, n. 3, p. 609618, 2008. 
MONTEIRO, F. S. Obtenção de suco de amora-preta (Rubus spp.) concentrado em antocianinas utilizando processos de separação por membranas. 2011. 135 f. Dissertação (Mestrado em Engenharia de Alimentos) - Programa de Pós-Graduação em Engenharia de Alimentos, Universidade Estadual de Campinas, Campinas, 2011.

NETZ, P. A.; ORTEGA, G. G. Fundamentos de físico-química: uma abordagem conceitual para as ciências farmacêuticas. Porto Alegre: Artmed, 2008.

PEGORINI, D. et al. Determinação da densidade e das características reológicas de frutas nativas da floresta com araucária. In: SEMINÁRIO DE INICIAÇÃO CIENTÍFICA E TECNOLÓGICA DA UTFPR, 17, 2012, Curitiba. Anais... Curitiba: UTFPR, 2012.

PINHEIRO, J. I. D. et al. Estatística básica: a arte de trabalhar com dados. Rio de Janeiro: Elsevier, 2009.

SANTOS, D. Q.; VIEIRA, D. F. Determinação de coeficiente de expansão térmica do biodiesel e seus impactos no sistema de medição volumétrico. Eclética Química, v. 35, n. 4, p. 107-112, 2010.

SOARES, S. E. Ácidos fenólicos como antioxidantes. Revista de Nutrição, v. 15, n. 1, p. 71-81, 2002.

SOUZA, D.; MARCZAK, L. D. F.; TESSARO, I. C. Seleção de metodologia para o estudo das propriedades físicas de sucos e polpas de pequenas frutas - amora, framboesa, morango e mirtilo. In: SEMINÁRIO DO PROGRAMA DE PÓS-GRADUAÇÃO EM ENGENHARIA QUÍMICA, 6, 2007, Porto Alegre, Anais... Porto Alegre: UFRGS, 2007.

YOUNG, H. D.; FREEDMAN, R. A. Física III - termodinâmica e ondas. São Paulo: Addison Wesley, 2008. 